\title{
SOBRE QUANDO É PRECISO CATAR SENTIDOS...*
}

Rejane Maria Arce Vargas ${ }^{* *}$

\section{Introdução}

Neste trabalho, objetivamos fazer uma leitura respeitante ao modo de significar a cidade, valendo-nos, para esse exercício de reflexão, do livro de poemas intitulado Catando Cidadania, lançado na 31a Feira do Livro de Santa Maria (RS), de autoria de Tereza da Silva, então integrante de grupo de catadores de materiais recicláveis nessa cidade. Para entender esse dizer, em suas condições de produção, analisamos recortes de poesias, ancorandonos em estudos da Análise de Discurso de linha francesa a que se filiam a pesquisadora Eni P. Orlandi e colaboradores, em especial os que têm como foco a compreensão das formas de significar as cidades - as "falas desorganizadas".

O espaço sócio-histórico onde esses textos foram produzidos constitui-se elemento estruturante desta análise - a cidade, Santa Maria (RS), pois é nela que o sujeito é interpelado a significar, na medida em que os sentidos circulam por ela. Nesse processo, o espaço de vida em comum é afetado por formações imaginárias, ficando circunscrito à ilusão de transparência dos sentidos. O sujeito busca significar-se numa cidade atravessada por sentidos/discursos que funcionam em relação a uma história de dizeres que os precedem. Assim, investigamos de que forma se constitui o sujeito em face desse jogo simbólico, uma vez que a cidade se mostra em linguagem no sujeito e este, por sua vez, em sujeito na cidade, num jogo em que ambos tomam corpo e (se)significam.

Iniciamos a reflexão pela descrição das condições de produção - flashes de uma discursividade urbana em constituição.

\footnotetext{
* Texto elaborado a partir das discussões estabelecidas nas aulas-seminário do projeto "Constituir, Formular e Fazer Circular Sentidos: Dispersão e Memória no Discurso sobre/na Cidade", vinculado ao Laboratório Corpus (PPGL/UFSM), as quais foram ministradas pela prof ${ }^{-a}$ Dr. Amanda E. Scherer, no período de agosto de 2004 a novembro de 2005.

** Doutoranda em Letras/Estudos Lingüísticos (PPGL-UFSM).
} 
No dia 14 de maio de 2004, Tereza Moraes Marques da Silva, então papeleira na cidade da Santa Maria (RS), lança um pequeno livro de poemas em que textualiza sua experiência junto ao grupo de catadores de materiais recicláveis do qual à época faz parte.

O livro Catando cidadania foi uma das realizações de projeto homônimo da Secretaria de Cultura do Município de Santa Maria (RS), a qual então desenvolvia ações que visavam à descentralização da cultura, adotando uma postura que buscava aproximar a coletividade dos processos de produção cultural. É nessa perspectiva que se insere o grupo de catadores do qual Tereza então faz parte, que se reunia semanalmente na Casa de Cultura para ensaiar as canções do Coral de Catadores, para desenvolver atividades teatrais, entre outras.

Engajado no processo de viabilização da publicação das poesias de Tereza esteve o projeto "Esperança Cooesperança". Este, vinculado à igreja católica, em conjunto com entidades representativas da sociedade, realiza atividades que objetivam promover a inclusão social por meio de projetos associativistas e de geração alternativa de renda ${ }^{1}$.

Considerados tais elementos das condições de produção do discurso, foram recortados enunciados marcados ideologicamente como circunscritos ao discurso do Partido dos Trabalhadores (PT), que então administrava a cidade de Santa Maria, bem como ao discurso teológico, que encontra referência na Teologia da Libertação e tem como um de seus expoentes, no Brasil, Leonardo Boff.

Com esse olhar, buscamos apreender como o dizer de Tereza produziu sentidos na/da cidade, diante desse atravessamento por diferentes saberes discursivos que têm como escopo o discurso da inclusão social.

Como material de apoio, foram utilizadas reportagens publicadas em jornal local, o qual deu "notoriedade" à Tereza, situando a questão no âmbito de um imaginário que ressoa em sentidos como "vejam, leiam, uma catadora lançou um livro de poesias na feira do livro da "cidade cultura-universitária".

Para proceder às análises, adotamos a perspectiva da narratividade urbana, que vem sendo estudada por Eni Orlandi e

1 Cf. informações captadas na Web em: <http://www.diocesesantamaria.org.br/>. Acesso em 30 de agosto de 2004. 
colaboradores, em especial nas obras Cidade Atravessada: Os Sentidos Públicos no Espaço Urbano (2001a) e Cidade dos Sentidos (2004), cujos autores têm buscado entender a cidade enquanto espaço polifônico, de multiplicidade de vozes que falam de dentro dos contextos de produção, assim como: a discursividade inscrita no rap, instalado em lugares onde a violência se faz presente; na poesia urbana; na conversa cotidiana; nas pichações; nos grafites; sobretudo, em dizeres que dão materialidade às cidades, nas múltiplas nuances do discurso urbano atual. Tais estudos buscam atravessar o imaginário que circunda e estanca esses dizeres e dar visibilidade à ordem do real, mediante a ruptura com a organização administrativa dos discursos nas cidades.

\section{Da circulação e do movimento dos sentidos}

Em relação ao aspecto hierárquico da cidade, importa aqui ressaltar a verticalização que vem sendo esboçada nos centros urbanos: "o centro é habitado pelos pobres, pelos meninos de rua, comércio informal, misturados a antigos resíduos do centro valorizado" (ORLANDI, 2001, p. 188), enquanto que os ricos [ou a classe média] estariam se deslocando para os condomínios fechados, por exemplo.

É no centro da cidade que os catadores atuam. Se, por um lado, sob a ótica do imaginário urbano, o catador é visto como o 'lixeiro', aquele que desorganiza a lixeira dos grandes condomínios, por outro, é nesse mesmo "centro" que vamos encontrar a desordem ecológica ou mesmo o descaso com aqueles que sobrevivem da reciclagem.

No dizer de Tereza, vamos poder observar o deslocamento do sentido de 'lixo'. Para o catador, lixo não é o todo, mas a parte significativa reutilizável, que pode ser reaproveitada e reverter-se então, em comida na mesa, desde que os materiais sejam devidamente separados. Assim, o que é lixo para alguns, é sustento, é 'garantia de pão na mesa' para outros.

Nesse sentido, podemos fazer referência à questão da constituição dos sentidos postulada por Pêcheux:

(...) as palavras, expressões, proposições, etc., mudam de sentido segundo as posições sustentadas por aqueles que as empregam, o que quer dizer que elas adquirem seu sentido em referências a essas

fragmentum, n. 16. Laboratório Corpus: UFSM, 2008. 
posições, isto é, em referência às formações ideológicas... (PÊCHEUX, 1995, p. 160) ${ }^{2}$.

Interessa-nos, especialmente a palavra lixo. O catador desorganiza o espaço urbano, aquele que, segue um "planejamento que simula uma cidade organizada" (ORLANDI, 2001a, p. 11). O catador mexe no "lixo", desorganiza-o, desloca seu sentido. Percebemos então que a língua tem uma forma material que não é transparente, mas opaca e está sujeita ao equívoco, e que esta forma apenas poder ser vislumbrada mediante a historicização do dizer. Ao se admitir a transparência de sentidos, estar-se-ia desconsiderando o imaginário a que os sujeitos estão expostos - as imagens prévias e pré-construídas dos objetos simbólicos (imagem que se tem de um professor, dona-de-casa, presidente, lixeiro, catador etc.), além do político e do ideológico que interferem nesse processo, uma vez que:

\footnotetext{
Pela ideologia, se naturaliza assim o que é produzido pela história: há transposição de certas formas materiais em outras, isto é, há simulação (...) em que são construídas transparências (...) para serem interpretadas por determinações históricas que aparecem como evidências empíricas (ORLANDI, 1996, p. 31).
}

Em uma perspectiva discursiva, ao mesmo tempo em que se quer o distanciamento da transparência dos sentidos, admite-se que os sujeitos (se)significam mediante um jogo de já-ditos (memória do dizível - interdiscurso), no entanto, no "mesmo", é preciso levar em conta as condições de produção em que o já-dito adquire plasticidade, entra em movimento, em que atuam o político, 0 ideológico, ao que o indivíduo é assujeitado.

Com esse enfoque, a cidade é tomada como "espaço simbólico particular tendo sua materialidade que produz sua própria forma de significar" (ORLANDI, 2001, p. 186). Nesse espaço coletivo, onde a quantidade é estruturante, circulam sentidos "comuns". Em que pese o entendimento de comum como algo banal ou relativo ao que é 'de todos', nessa dicotomia, instala-se o sentido discursivo: "traço de discursos prévios, cuja origem já está apagada em uma formulação particular, mas necessária ao espaço comum

2 Grifos no texto. 
da sociabilidade (...) não há opinião pública sem idéias recebidas, sem lugar comum" (ORLANDI, 2001, p.197-198).

O lugar-comum expande-se no estereótipo, no clichê, no estabilizado do imaginário urbano. Orlandi (2001a) não busca explicar o estereótipo (um estabilizado da ordem do imaginário), "mas, no movimento entre descrição e interpretação" (Ibid., p.18), procura compreendê-lo no funcionamento do discurso urbano, ou seja, o comum como prática historicizada.

\section{Do comum ao divergente - espaço de interpretação}

A interpretação se coloca como pressuposto basilar para a $A D$, ao passo que não há sentido sem interpretação, a qual se instaura mediante a relação da língua com a história, ideologicamente instituída.

Todo enunciado é intrinsecamente suscetível de tornar-se outro, diferente de si mesmo, se deslocar discursivamente de seu sentido para derivar para um outro (...). Todo enunciado, toda seqüência de enunciados é, pois, lingüisticamente descritível como uma série (...) de pontos de deriva possíveis, oferecendo lugar à interpretação (PÊCHEUX, 1990, p. 53).

O espaço de interpretação não está aberto a tudo, pois esta não pode ser qualquer uma, já que, nesse sítio, intervém, além da materialidade lingüística, a discursiva, o social, o histórico, o ideológico. Para dar visibilidade ao processo histórico-discursivo que constitui a maneira pela qual um objeto simbólico produz sentidos, fizemos recortes. A noção de recorte que adotamos é a postulada por Orlandi tal como "fragmentos correlacionados de linguagem e situação", ou seja, "um fragmento da situação discursiva" (ORLANDI, 1984, p. 14).

Os estudos sobre as falas urbanas (ORLANDI, 2001; 2001a) tratam do que, em uma ótica des-historicizada, circularia como banalidade, como chavões, entre outros designativos desqualificadores, em que poderiam ser inseridos, por exemplo:

Recorte 1 (trechos do poema Nossa profissão):

Nós somos catadores, é a nossa profissão, 


\section{Por falta de estudo, Deus nos deu essa missão.}

Trabalhamos com orgulho e garantimos nosso pão, $(\ldots)^{3}$

Dentro da organização urbana, sob um olhar organizado, esses enunciados engendram sentidos que beiram ao vulgar, ao senso comum essencialista, no entanto, instalados numa situação cotidiana de busca pelo sustento e tentativa de justificação "simbólica" para uma situação econômico-social adversa, divergem, reivindicam sentidos outros, de modo que o sentido se movimenta na história, pois, como lembra Orlandi (2001, p. 201):

(...) a prática historicizada da repetição, do comum desloca o senso comum, o automatismo, o fixado. À formação discursiva centrada nos sentidos de convergir, reunir, globalizar, comunicar, interagir, instrumentalizar, transformar, devido às (disciplinados pelas) injunções da normatividade social (o politicamente correto), responde a narratividade urbana com a divergência, a des-transformação, o dissenso.

De acordo com Pêcheux, o discurso "não se trata necessariamente de uma transmissão de informação entre A e B, mas, de modo mais geral, de um 'efeito de sentidos' entre os pontos A e B" (1993, p. 82). É a partir de sua relação com os outros, nas diferentes formações discursivas que emergem do urbano, que Tereza então (se)significa. Em seu modo de dizer, observa-se um entrelaçamento do discurso político-religioso, do "profissional" relativo ao pragmatismo concernente a sua ocupação como papeleira, com sua história pessoal. A esse respeito, vejamos, um exemplo:

Recorte 2 (trecho do poema A papeleira)

Os catadores são humildes

Sejam da cor que forem

Às vezes discriminados

Pela profissão que temos

Nós nunca desanimamos

E não nos envergonhamos

Nós todos somos humanos

Igual a qualquer outro homem

3 Grifos nossos. 
Deus deu sorte para uns

Sacrifício para outros $(\ldots)^{4}$

Tereza, juntamente com seu grupo, se afirma catadora por profissão, deixando um espaço determinante ao qual se pode acrescentar uma ressalva: nós somos catadores, MAS é por falta de estudo; por outro lado, ela sente-se orgulhosa em garantir a subsistência, ao mesmo tempo em que se coloca em condição de humildade. Ao falar em cor, discriminação figura em seguida, logo ressalvado, o sentido aí colocado, ao expressar que não se envergonha do que faz, do que é, pois postula igualdade e, em seguida, a diferença: as diferenças sociais são atribuídas a uma dimensão transcendental, ou seja, Deus determinaria a quem competiria o sacrifício e a quem a sorte. É num vai-e-vem que esse dizer se constitui, sentidos se contrapõem, trazem um sim e um não implicados, mutuamente.

Percebe-se, nessa discursividade, um sujeito afetado pelo real da cidade, mediante um dizer que se move entre a afirmação do ideal de cidadania e de inclusão social e as limitações impostas pelo político, pelo social; um sujeito que traz consigo sentidos que se formulam face à convivência com um grupo de catadores, que é, à época: atrelado a uma organização da cidade (Casa de Cultura), cuja administração é então exercida pelo Partido dos Trabalhadores (PT), a qual realiza ações de inclusão social em cooperação com a igreja católica, lideradas por sujeitos que presentificam a discursividade religiosa da Teologia da Libertação (TL) (cf. ORLANDI, 1996).

É desse real do urbano que Tereza convoca sentidos para seu discurso, ela se inscreve com eles, embora não tenha controle sobre esse processo. Desorganiza uma discursividade para instalar a sua em sujeito, instado ao equívoco, à incompletude. Em seu dizer, movimenta essencialidades burocrático-burguesas ("Deus nos deu essa missão"; somos pobres, mas temos orgulho; trabalhamos duro, mas somos felizes etc.), como também traz a denúncia do preconceito racial e das desigualdades (inscreve-se no discurso do PT). Ao mesmo tempo, trata da luta pela inclusão social, da fé e do engajamento solidário contra a pobreza (inscreve-se no discurso religioso da $\mathrm{TL}$ ). Isso tudo para sustentar, na instância

4 Grifos nossos.

fragmentum, n. 16. Laboratório Corpus: UFSM, 2008. 
argumentativa, os dizeres de quem busca afirmar-se em sujeito. Tereza produz sentidos na ordem em que esses discursos instaurados na cidade afetam-na em sua prática simbólica, "trazendo à tona, mesmo sem saber, a equivocidade do "comum", a complexidade do "público", a não-transparência da construção da opinião, sua historicidade" (ORLANDI, 2001, p. 22) ${ }^{5}$, pois a papeleira diz que a "Cidade universitária/ Cheia encantos mil.../ Sei que ela não me ama/ E jamais poderá me amar"[??] (poema "Eu não sou daqui").

\section{Considerações finais}

O indivíduo, interpelado a se subjetivar pela linguagem, poderia pressupor que sabe o que diz, e significa só aquilo que 'quer' significar. Sabemos, no entanto, por Orlandi (1999, p. 32), que: "O sujeito diz, pensa que sabe o que diz, mas não tem acesso ou controle sobre o modo pelo qual os sentidos se constituem nele."

Ao fazer uso da fala comum, Tereza se significa enquanto cidadã do papel, ou seja, o papel, em sua estruturação simbólica e política, faz com que esse sujeito deixe de textualizar o óbvio do comum para, em seu gesto, de dentro das condições de produção, significar-se, de modo a re-significar o comum da dispersão, trazendo recortes polifônicos para seu texto escrito, dando a ele sua autoria, seu modo de interpretar, numa cidade atravessada de sentidos.

Por meio dessa reflexão, percebemos que o sujeito não exerce controle sobre seu dizer, uma vez que os sentidos sempre 'já são/estão' antes dele, e porque convoca diferentes formações discursivas e o imaginário social para significar, como forma de sustentar "sua" opinião em relação a sua experiência com o mundo, com a cidade. Traz à tona, assim, a equivocidade da linguagem, sua incompletude, de modo que o mesmo, o comum, analisado em suas condições de produção, emoldura sentidos que se movimentam no jogo simbólico em que o indivíduo se faz sujeito.

5 Grifos da autora. 


\section{Referências bibliográficas}

DOMINGUEZ, Carlos. Tereza, simplesmente demais. Diário de Santa Maria, Santa Maria, 15 e 16 mai. 2004.

ORLANDI, Eni P. Discurso e Texto: Formulação e Circulação dos Sentidos. Campinas, SP: Pontes, 2001.

Tralhas e troços: o flagrante urbano. In: Cidade Atravessada: Os Sentidos Públicos do Espaço Urbano. Campinas, SP: Pontes. p. 9-24, 2001(a).

Análise de Discurso: Princípios e Procedimentos. Campinas, SP: Pontes, 1999.

. Interpretação: Autoria, Leitura e Efeitos do Trabalho Simbólico. Petrópolis, RJ: Vozes, 1996.

Segmentar ou recortar. In: Lingüística: Questões e Controvérsias. Uberaba: MG, 1984.

PÊCHEUX, Michel. O Discurso: Estrutura ou Acontecimento. Trad. de Eni P. Orlandi. Campinas, SP: Pontes, 1990.

Análise Automática do Discurso (AAD-69). In: GADET, Françoise; HAK, Tony (Orgs.). Por uma Análise Automática do Discurso: Uma Introdução à Obra de Michel Pêcheux. 2. ed. Trad. de Bethania Mariani [et al]. Campinas, SP: Unicamp, 1993.

Semântica e Discurso: Uma Crítica à Afirmação do Óbvio. Trad. de Eni Orlandi [et al.]. 2. ed. Campinas: SP, 1995.

PORCIÚNCULA, Bruna. Tereza Silva, escritora. Diário de Santa Maria (2), Santa Maria, 14 mai., 2004.

SILVA, Tereza Moraes Marques da. Catando Cidadania. Santa Maria, RS: Pallotti, 2004. 